\title{
Effects of Polymorphisms in Myc-Related Genes on Bleeding Complications in Patients with Stable Warfarin Responses
}

\author{
Jeong Yee $\mathbb{D},{ }^{1}$ Woorim Kim $\mathbb{D},{ }^{2}$ Byung Chul Chang, ${ }^{3,4}$ Jee Eun Chung $\mathbb{D},^{5}$ \\ Kyung Eun Lee $\left(\mathbb{1},{ }^{2}\right.$ and Hye Sun Gwak $\left(\mathbb{1}^{1}\right.$ \\ ${ }^{1}$ College of Pharmacy \& Division of Life and Pharmaceutical Sciences, Ewha Womans University, 52 Ewhayeodae-gil, \\ Seodaemun-gu, Seoul 03760, Republic of Korea \\ ${ }^{2}$ College of Pharmacy, Chungbuk National University, 660-1, Yeonje-ri, Osong-eup, Heungdeok-gu, \\ Cheongju-si 28160, Republic of Korea \\ ${ }^{3}$ Department of Thoracic and Cardiovascular Surgery, Bundang CHA Medical Center, CHA University, 59 Yatap-ro, \\ Bundang-gu, Seongnam, Gyeonggi-do, Republic of Korea \\ ${ }^{4}$ Department of Thoracic \& Cardiovascular Surgery, Yonsei University Medical Center, 50-1 Yonsei-ro, Seodaemun-gu, \\ Seoul 03722, Republic of Korea \\ ${ }^{5}$ College of Pharmacy, Hanyang University, 55 Hanyangdeahak-ro, Sangnok-gu, Ansan 15588, Republic of Korea
}

Correspondence should be addressed to Kyung Eun Lee; kaylee@cbnu.ac.kr and Hye Sun Gwak; hsgwak@ewha.ac.kr

Received 9 February 2019; Accepted 28 April 2019; Published 8 May 2019

Academic Editor: Leonardo De Luca

Copyright @ 2019 Jeong Yee et al. This is an open access article distributed under the Creative Commons Attribution License, which permits unrestricted use, distribution, and reproduction in any medium, provided the original work is properly cited.

Objectives. This study aimed to identify the possible effects of $M y c$ and 8q24 polymorphisms on bleeding complications in patients who maintained international normalized ratio (INR) of 2.0-3.0 with warfarin therapy after cardiac valve replacement. Methods. Twenty-five single nucleotide polymorphisms were analyzed, including VKORC1, CYP2C9, Myc, and 8q24. Univariate and multivariate analyses were conducted to evaluate the associations between genetic polymorphisms and bleeding complications. Attributable risk and the number needed to genotype (NNG) were also calculated to evaluate the potential clinical value of genotyping. Results. We included 142 patients, among whom 21 experienced bleeding complications. Multivariate models showed that patients carrying the CC genotype of rs6983561 and the A allele of rs13281615 at 8q24 had 27.6- and 10.0-fold higher bleeding complications, compared with patients with the A allele and the GG genotype, respectively. For rs6983561, the attributable risk and NNG were $96.4 \%$ and 36.8, respectively, whereas, for rs13281615, the attributable risk and NNG were $90.0 \%$ and 8.3 , respectively. Atrial fibrillation was associated with a 5.5-fold increased risk of bleeding complications. The AUROC value was 0.761 (95\% CI $0.659-0.863, \mathrm{p}<0.001)$, and the Hosmer-Lemeshow test showed that the fitness of the multivariate analysis model was satisfactory $\left(\chi^{2}=0.846 ; 3\right.$ degrees of freedom; $\left.\mathrm{p}=0.838\right)$. Conclusions. Bleeding complications during warfarin therapy were associated with $8 \mathrm{q} 24$ polymorphisms and atrial fibrillation in patients with mechanical heart valves.

\section{Introduction}

Warfarin is a widely used anticoagulant, and its effectiveness is well established, mainly for preventing and treating atrial fibrillation, ischemic stroke, deep vein thrombosis, and pulmonary embolism $[1,2]$. Although an introduction of direct oral anticoagulants has attracted many patients, warfarin still remains the first-line anticoagulant for patients with heart valve prostheses [3]. However, warfarin has several shortcomings, such as a narrow therapeutic range and wide inter- and intra-individual variability. Hence, warfarin administration requires close monitoring, using the international normalized ratio (INR) [4].

The most common adverse effect of warfarin is bleeding. Even though an elevated INR is correlated with an increased warfarin-associated bleeding risk, bleeding complications also can be seen in patients at a therapeutic INR [5]. Some studies have demonstrated that-in addition to a high INR-age, hypertension, and concomitant aspirin use were patient-related risk factors for bleeding complications $[5,6]$. 
Although Myc has potential roles in vascular regulation, to our knowledge, no study has yet investigated the association between $M y c$ gene polymorphisms and bleeding complications in patients receiving warfarin.

Myc is known as a transcription factor of many different genes, and its predominant role is to increase the production of transcripts from active genes [7]. Among many functions, Myc is involved in angiogenesis-related gene expression in a cell-dependent manner [8]. Polymorphisms of $M y c$ have been shown to result in vascular malformation [8], thereby increasing bleeding risks [9]. In this context, polymorphisms of $M y c$ could induce bleeding complications, especially in patients at risk of bleeding, such as those receiving warfarin treatment.

Chromosome 8q24 is enhancer and physically interacts with $M y c$ [10]. Since 8q24 has roles in $M y c$ promoter activity, polymorphisms of $8 \mathrm{q} 24$ could affect Myc functions, including those related to vascular malformation [11]. Therefore, it is reasonable to speculate that polymorphisms of $8 \mathrm{q} 24$ could lead to bleeding complications. Although patients undergoing warfarin therapy are vulnerable to bleeding complications, there is no study on the association between $M y c$ or $8 \mathrm{q} 24$ gene polymorphisms and bleeding in patients on warfarin.

Therefore, this study aimed to investigate the association between Myc-associated polymorphisms and the risk of bleeding complications in patients who maintained an INR between 2.0 and 3.0 with warfarin therapy after cardiac valve replacement.

\section{Materials and Methods}

2.1. Study Patients and Data Collection. Study patients were included from the Ewha-Severance Treatment (EAST) Group of Warfarin, which consists of 229 patients who received warfarin after mechanical heart valve replacement between January 1982 and December 2009 at Severance Cardiovascular Hospital of Yonsei University College of Medicine. Patients who maintained a stable INR (INR between 2.0 and 3.0 for at least three consecutive measurements) were eligible for the study. We excluded patients who experienced bleeding complications under conditions of supra- or subtherapeutic INR. Patients were also excluded if their complications were not verified by health professionals.

Patients were followed up continuously at the outpatient clinic of Severance Cardiovascular Hospital of Yonsei University Medical Center. Blood samples were collected during regularly scheduled clinic visits. Data collection was performed retrospectively from scanned medical records and electronic medical records of patient visits that occurred between June 1983 and August 2010. Data including gender, age, body weight, height, position of valve prosthesis, valve type, warfarin therapy duration, INR measurements, concurrent medication, comorbidities, and history of bleeding complications were collected. Bleeding complications were classified as major life-threatening, other major, any major, minor, or minimal using the scheme detailed in the Platelet Inhibition and Patient Outcomes (PLATO) trial [12].
This study was approved by the Institutional Review Board of the Yonsei University Medical Center (approval number: 4-2009-0283). All patients gave written informed consent for participation.

2.2. Genotyping Methods. To select single nucleotide polymorphisms (SNPs) of Myc and 8q24 that might be associated with warfarin-related bleeding, genetic information concerning $M y c$ and 8q24 was obtained from the PharmGKB database, Haploreg 4.1, and the National Center for Biotechnology (NCBI) SNP Database (dbSNP), as well as previous studies [10, 13-18]. Five Myc SNPs (rs4645957, rs4645948, rs4645962, rs4645943, and rs4645974) and 18 8q24 SNPs (rs6983267, rs1447295, rs4242382, rs4242384, rs7837688, rs16902094, rs4451114, rs1456315, rs6983561, rs16901979, rs10505483, rs13252298, rs1016343, rs10505477, rs9642880, rs13281615, rs1562430, and rs7014346) were selected. In addition to the selected SNPs, VKORC1 rs9934438 and CYP2C9 rs1057910, which were found to have significant effects on stable doses of warfarin, were also included in the study. Therefore, a total of 25 SNPs was investigated.

Genomic DNA from the patients was isolated from ethylenediaminetetraacetic acid-blood samples using the QIAamp DNA Blood Mini Kit (QIAGEN GmbH, Hilden, Germany) according to the manufacturer's instructions. Genotyping was carried out using a single-base primer extension assay and SNaPShot multiplex kits (ABI, Foster City, CA, USA) or the TaqMan genotyping assay with a realtime polymerase chain reaction (PCR) system (ABI 7300, $\mathrm{ABI}$, Foster City, CA, USA), according to the manufacturer's instructions.

2.3. Statistical Analysis. Continuous variables in patients with bleeding complications and those without complications were compared using Student's t-test. Chi-square analysis was used to compare categorical variables between the two groups. Multivariate logistic regression analysis was used to examine the independent risk factors for bleeding complications. Factors having $p$ values less than 0.05 from univariate analysis along with clinically relevant confounders were included in the multivariate analysis. Odds ratio (OR) and adjusted odds ratio (AOR) were calculated from the univariate and multivariate analyses, respectively. Attributable risk (\%) was calculated using the formula $(1-1 / \mathrm{AOR}) \times$ 100. To test the model's goodness of fit, we performed a Hosmer-Lemeshow test. Discrimination of the model was further assessed by an analysis of the area under the receiver operating curve (AUROC), which assesses the ability of the risk factor to predict bleeding. We calculated the number needed to genotype (NNG) for preventing one patient from experiencing a significantly higher incidence of bleeding complications by $1 /$ absolute risk reduction. Absolute risk reduction was calculated by multiplying the relative risk reduction via genotyping by the risk of higher incidence of bleeding complications without genotyping. A $p$ value of less than 0.05 was considered statistically significant. All statistical analyses were carried out using IBM SPSS Statistics, 
version 20 software (International Business Machines Corp., New York, USA).

\section{Results}

Of 229 patients in the EAST Group of Warfarin, 87 patients were excluded due to the following reasons: 28 patients did not reach stable INR, 4 patients had bleeding complications at supratherapeutic INR, and 55 patients had reportedly minimal bleeding complications that were not verified by health professionals. Accordingly, data from 142 patients who underwent cardiac valve replacement were included in the analysis.

The median age of included patients was 60 years (range 34-81 years). There were $52(36.6 \%)$ males. The followup periods ranged from 1.0 to 29.7 years. The mean INR monitoring interval was 2.9 months, and the average number of INR measurements per patient was 23. As shown in Table 1, 21 patients $(14.8 \%)$ had bleeding complications at therapeutic INR. Among them, 11 patients and 10 patients experienced minor bleeding and minimal bleeding complications, respectively. There were 31 bleeding episodes in 21 patients during study period. No significant difference was found between the two groups except for atrial fibrillation. Patients with atrial fibrillation had more bleeding complications at therapeutic INR than patients without atrial fibrillation $(\mathrm{p}=0.045)$.

As shown in Table 2, statistically significant associations between genotypes and bleeding complications were found for rs6983561, rs16901979, rs10505483, and rs13281615 of 8q24. There was linkage disequilibrium (LD) among rs6983561, rs16901979, and rs10505483 $\left(\mathrm{r}^{2}>0.95\right)$. Patients with the CC genotype in rs6983561 (AA genotype in rs16901979 and TT genotype in 10505483) experienced more bleeding complications than A allele (C allele in rs16901979 and rs10505483) carriers $(44.4 \%$ vs $12.8 \%, \mathrm{p}=0.010)$. For rs13281615, patients with the A allele showed higher bleeding risks, compared with those with variant-type homozygote (19.0\% vs $4.8 \%$, $\mathrm{p}=0.029$ ).

The multivariate analysis (Table 3 ) included sex, age, and factors having $\mathrm{p}<0.05$ from the univariate analysis, including atrial fibrillation, rs6983561, and rs13281615 of 8q24. Because significant LD was observed between rs6983561, rs16901979, and rs10505483, only rs6983561 was included in the multivariate analysis. Among included factors, atrial fibrillation, rs6983561, and rs13281615 were significantly associated with bleeding complications $(p=0.021, p=0.001$, and $\mathrm{p}=0.019$, respectively). After adjusting for related covariates, CC genotype carriers in rs6983561 showed about a 27.6-fold higher bleeding complication rate than A allele carriers. For rs13281615, A allele carriers had about a 10.0-fold higher bleeding complication rate than those with the GG genotype. Patients with atrial fibrillation had a 5.5-fold higher bleeding complication rate at a therapeutic INR than those without atrial fibrillation. The NNG for preventing one patient with the CC genotype in rs6983561 from suffering a higher incidence of bleeding complications was 36.8 , and the NNG for rs13281615 was 8.3.

The AUROC value was 0.761 (95\% confidence interval [CI] 0.659-0.863, p<0.001) (Figure 1). The Hosmer-Lemeshow test

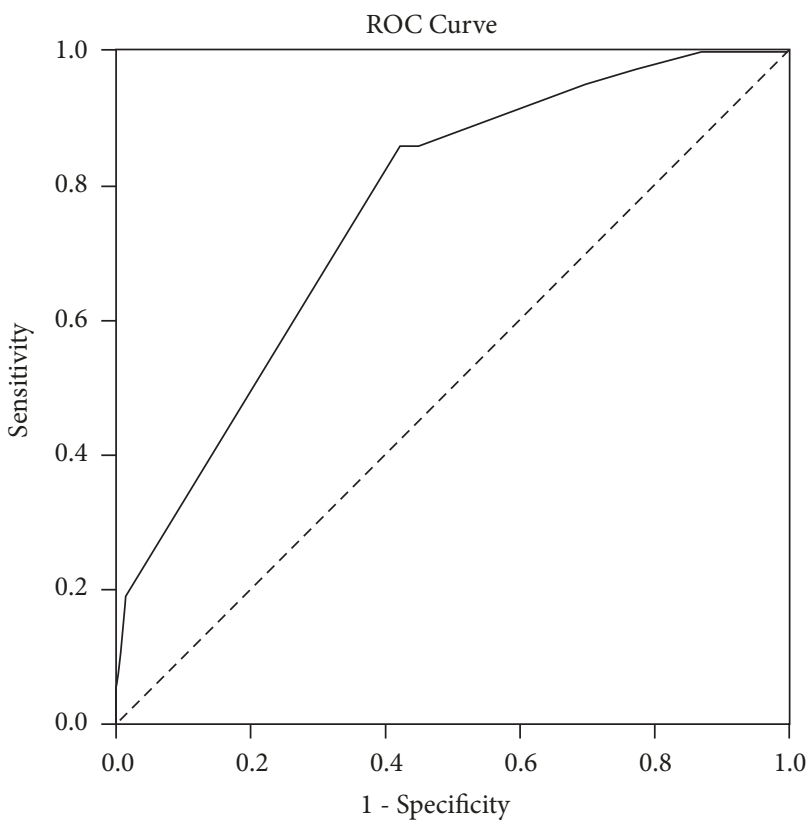

FIGURE 1: Area under receiver operating characteristic curve for bleeding complications at a therapeutic INR. Model included sex, age, atrial fibrillation, rs6983561, and rs13281615 for analysis. AUC is 0.761 (95\% CI 0.659-0.863, $\mathrm{p}<0.001)$.

showed that the fitness of the multivariate analysis model was satisfactory $\left(\chi^{2}=0.846 ; 3\right.$ degrees of freedom; $\left.\mathrm{p}=0.838\right)$.

\section{Discussion}

The results of this study suggested that two SNPs of 8q24 (rs6983561 and rs13281615) were associated with bleeding complications at a therapeutic INR during warfarin treatment for mechanical heart valve patients. CC genotype carriers of rs6983561 were 27.6 times (95\% CI 3.6-210.3) more likely to experience bleeding complications, compared with A allele carriers, and the attributable risk was 96.4\%. After adjusting for related covariates, A allele carriers in rs13281615 were about 10.0 times more likely to experience bleeding complications than those with the GG genotype (95\% CI 1.5-68.6); the attributable risk was 90.0\%. Among comorbidities, atrial fibrillation was the only significant risk factor for bleeding complications after adjusting for covariates. The AUROC value of the multivariate analysis model for predicting bleeding complications was 0.76 .

$M y c$, which is located on chromosome $8 \mathrm{q} 24$, is a transcription factor regulating $10-15 \%$ of all cellular genes. It is involved in cell progression, differentiation, apoptosis, and neoplasia [19]. It is widely known as a protooncogene; however, a previous study has found that it is also related to cardiovascular diseases [20]. Myc is reported to have critical roles in angiogenesis, and it has been suggested that it coordinates the angiogenic network as a master regulator [21]. The proper expression of Myc has been shown to be essential for vessel formation and smooth muscle cell proliferation $[8,22]$. 
TABLe 1: Patient characteristics of study patients.

\begin{tabular}{|c|c|c|c|}
\hline \multirow{2}{*}{ Characteristics } & \multicolumn{2}{|c|}{ Bleeding complication, number (\%) } & \multirow{2}{*}{$p$} \\
\hline & Presence $(n=21)$ & Absence $(\mathrm{n}=121)$ & \\
\hline Sex & & & 0.705 \\
\hline Male & $8(38.1)$ & $44(36.4)$ & \\
\hline Female & $13(61.9)$ & $77(63.6)$ & \\
\hline Age (years) & & & 0.106 \\
\hline Mean \pm SD & $62.0 \pm 11.2$ & $58.7 \pm 10.0$ & \\
\hline Body weight (kg) & & & 0.989 \\
\hline Mean \pm SD & $58.6 \pm 10.7$ & $58.7 \pm 10.4$ & \\
\hline Body mass index $\left(\mathrm{kg} / \mathrm{m}^{2}\right)$ & & & 0.756 \\
\hline Mean \pm SD & $22.3 \pm 2.3$ & $22.5 \pm 2.8$ & \\
\hline \multicolumn{4}{|l|}{ Comorbidity } \\
\hline Hypertension & $6(28.6)$ & $33(27.3)$ & 0.902 \\
\hline Diabetes mellitus & $3(14.3)$ & $10(8.3)$ & 0.377 \\
\hline Chronic heart failure & $7(33.3)$ & $25(20.7)$ & 0.199 \\
\hline Atrial fibrillation & $17(81)$ & $70(57.9)$ & 0.045 \\
\hline Myocardial infarction & $2(9.5)$ & $2(1.7)$ & 0.104 \\
\hline \multicolumn{4}{|l|}{ Comedication } \\
\hline Angiotensin-converting-enzyme inhibitor & $2(10.5)$ & $19(18.8)$ & 0.383 \\
\hline Angiotensin II receptor blocker & $4(21.1)$ & $19(18.8)$ & 0.820 \\
\hline Antiplatelet drugs & $0(0)$ & $4(3.8)$ & 0.398 \\
\hline Calcium channel blocker & $4(21.1)$ & $19(18.8)$ & 0.820 \\
\hline Diuretics & $9(47.4)$ & $35(34.7)$ & 0.291 \\
\hline Statins & $0(0)$ & $4(4.0)$ & 0.378 \\
\hline Valve position & & & 0.740 \\
\hline Aortic & $6(28.6)$ & $28(23.1)$ & \\
\hline Mitral & $9(42.9)$ & $66(54.5)$ & \\
\hline Double $^{\mathrm{a}}$ & $5(23.8)$ & $20(16.5)$ & \\
\hline Tricuspid $^{\mathrm{b}}$ & $1(4.8)$ & $7(5.8)$ & \\
\hline Valve type & & & 0.418 \\
\hline St. Jude Medical & $7(38.9)$ & $39(34.2)$ & \\
\hline CarboMedics & $6(33.3)$ & $32(28.1)$ & \\
\hline ATS & $2(11.1)$ & $15(13.2)$ & \\
\hline MIRA & $1(5.6)$ & $9(7.9)$ & \\
\hline Duromedics & $2(11.1)$ & $6(5.3)$ & \\
\hline OnX & $0(0)$ & $4(3.5)$ & \\
\hline Others $^{c}$ & $0(0)$ & $9(7.9)$ & \\
\hline International normalized ratio & & & 0.143 \\
\hline Mean \pm SD & $2.41 \pm 0.07$ & $2.45 \pm 0.10$ & \\
\hline Follow-up time (years) & & & 0.886 \\
\hline Median (range) & $14.3(1.4-29.7)$ & $14.7(1.0-27.7)$ & \\
\hline
\end{tabular}

${ }^{a}$ Aortic plus mitral valve; ${ }^{b}$ tricuspid valve with or without other valves; ${ }^{c}$ including Sorin, Bjork Shiley, D-ring, and prostheses using two or more different valve types.

Hemostasis is a multiphase process involving blood vessels, platelets, and coagulation factors; an imbalance in any of the steps of hemostasis may result in bleeding [23]. Vascular malformation with unrestrained angiogenesis is among the causes of bleedings in several organs (e.g., gastrointestinal tract, retina, and endometrium) [24-26]. As Myc is involved in vascular formation and regulation, polymorphisms of the $M y c$ gene may lead to vascular malformation, thereby increasing the risk of bleeding complications, especially among patients taking warfarin.

Chromosome $8 \mathrm{q} 24$ is one of the gene deserts; however, it has been suggested that the $8 \mathrm{q} 24$ region has regulatory elements for the expression of Myc. It is shown that polymorphisms of $8 \mathrm{q} 24$ interact near the $M y c$ promoter region 
TABLE 2: Factors associated with bleeding complications at a therapeutic INR.

\begin{tabular}{|c|c|c|c|c|c|c|c|}
\hline \multirow{2}{*}{$\begin{array}{l}\text { Gene } \\
\text { polymorphism }\end{array}$} & \multirow[t]{2}{*}{ Allele change } & \multirow{2}{*}{$\begin{array}{l}\text { Minor allele } \\
\text { frequency }\end{array}$} & \multirow{2}{*}{$\begin{array}{l}\text { Grouped } \\
\text { genotypes }\end{array}$} & \multicolumn{2}{|c|}{$\begin{array}{c}\text { Bleeding complications, } \\
\text { number }(\%)\end{array}$} & \multirow[t]{2}{*}{ OR (95\% CI) } & \multirow[t]{2}{*}{$P$} \\
\hline & & & & $\begin{array}{c}\text { Presence } \\
(\mathrm{n}=21)\end{array}$ & $\begin{array}{l}\text { Absence } \\
(\mathrm{n}=121)\end{array}$ & & \\
\hline VKORC1 & $\mathrm{C}>\mathrm{T}$ & 0.113 & $\mathrm{CC}, \mathrm{CT}$ & $3(14.3)$ & $27(22.3)$ & 1 & 0.405 \\
\hline rs9934438 & & & $\mathrm{TT}$ & 18 (85.7) & $94(77.7)$ & $\begin{array}{c}1.72 \\
(0.47-6.29)\end{array}$ & \\
\hline CYP2C9 & $\mathrm{A}>\mathrm{C}$ & 0.043 & AA & $18(85.7)$ & $111(92.5)$ & 1 & 0.304 \\
\hline $\mathrm{rs} 1057910^{\mathrm{a}}$ & & & $\mathrm{AC}, \mathrm{CC}$ & $3(14.3)$ & $9(7.5)$ & $\begin{array}{c}2.06 \\
(0.51-8.32)\end{array}$ & \\
\hline $8 \mathrm{q} 24$ & $\mathrm{G}>\mathrm{T}$ & 0.384 & GG & $4(19.0)$ & $16(13.2)$ & 1 & 0.479 \\
\hline rs6983267 & & & GT, TT & $17(81.0)$ & $105(86.8)$ & $\begin{array}{c}0.65 \\
(0.19-2.17)\end{array}$ & \\
\hline $8 \mathrm{q} 24$ & $\mathrm{~A}>\mathrm{C}$ & 0.162 & AA & $0(0.0)$ & $2(1.7)$ & 1 & 0.553 \\
\hline rs1447295 & & & $\mathrm{AC}, \mathrm{CC}$ & $21(100.0)$ & 119 (98.3) & $\begin{array}{c}0.98 \\
(0.96-1.01)^{*}\end{array}$ & \\
\hline $8 \mathrm{q} 24$ & $A>G$ & 0.162 & AA & $0(0.0)$ & $5(4.1)$ & 1 & 0.343 \\
\hline rs4242382 & & & AG, GG & $21(100.0)$ & $116(95.9)$ & $\begin{array}{c}0.96 \\
(0.92-1.00)^{*}\end{array}$ & \\
\hline $8 \mathrm{q} 24$ & $\mathrm{C}>\mathrm{A}$ & 0.155 & $\mathrm{CC}$ & $0(0.0)$ & $4(3.3)$ & 1 & 0.398 \\
\hline rs4242384 & & & $\mathrm{CA}, \mathrm{AA}$ & $21(100)$. & 117 (96.7) & $\begin{array}{c}0.97 \\
(0.94-1.00)^{*}\end{array}$ & \\
\hline $8 \mathrm{q} 24$ & $\mathrm{~T}>\mathrm{G}$ & 0.141 & $\mathrm{TT}$ & $0(0.0)$ & $5(4.1)$ & 1 & 0.343 \\
\hline rs7837688 & & & TG, GG & $21(100.0)$ & $116(95.9)$ & $\begin{array}{c}0.96 \\
(0.92-1.00)^{*}\end{array}$ & \\
\hline $8 \mathrm{q} 24$ & $A>G$ & 0.278 & $\mathrm{AA}, \mathrm{AG}$ & $18(85.7)$ & $113(93.4)$ & 1 & 0.225 \\
\hline rs16902094 & & & GG & $3(14.3)$ & $8(6.6)$ & $\begin{array}{c}2.35 \\
(0.57-9.71)\end{array}$ & \\
\hline $8 \mathrm{q} 24$ & $\mathrm{~T}>\mathrm{C}$ & 0.454 & TT, TC & $16(76.2)$ & 99 (81.8) & 1 & 0.544 \\
\hline rs445114 & & & CC & $5(23.8)$ & $22(18.2)$ & $\begin{array}{c}1.41 \\
(0.47-4.25)\end{array}$ & \\
\hline $8 \mathrm{q} 24$ & $\mathrm{~T}>\mathrm{C}$ & 0.304 & TT, TC & $19(95.0)$ & $105(87.5)$ & 1 & 0.329 \\
\hline rs1456315 & & & $\mathrm{CC}$ & $1(5.0)$ & 15 (12.5) & $\begin{array}{c}0.37 \\
(0.05-2.96)\end{array}$ & \\
\hline $8 \mathrm{q} 24$ & $\mathrm{~A}>\mathrm{C}$ & 0.254 & $\mathrm{AA}, \mathrm{AC}$ & $17(81.0)$ & 116 (95.9) & 1 & 0.010 \\
\hline rs6983561 & & & $\mathrm{CC}$ & $4(19.0)$ & $5(4.1)$ & $\begin{array}{c}5.45 \\
(1.33-22.36)\end{array}$ & \\
\hline $8 \mathrm{q} 24$ & $\mathrm{C}>\mathrm{A}$ & 0.261 & $\mathrm{CC}, \mathrm{CA}$ & $17(81.0)$ & $116(95.9)$ & 1 & 0.010 \\
\hline rs16901979 & & & AA & $4(19.0)$ & $5(4.1)$ & $\begin{array}{c}5.46 \\
(1.33-22.36)\end{array}$ & \\
\hline $8 \mathrm{q} 24$ & $\mathrm{C}>\mathrm{T}$ & 0.261 & CC, CT & 17 (81.0) & $116(95.9)$ & 1 & 0.010 \\
\hline rs 10505483 & & & $\mathrm{TT}$ & $4(19.0)$ & $5(4.1)$ & $\begin{array}{c}5.46 \\
(1.33-22.36)\end{array}$ & \\
\hline $8 \mathrm{q} 24$ & $A>G$ & 0.292 & $\mathrm{AA}, \mathrm{AG}$ & $17(81.0)$ & $106(87.6)$ & 1 & 0.409 \\
\hline rs13252298 & & & GG & $4(19.0)$ & $15(12.4)$ & $\begin{array}{c}1.66 \\
(0.49-5.61)\end{array}$ & \\
\hline $8 \mathrm{q} 24$ & $\mathrm{C}>\mathrm{T}$ & 0.340 & $\mathrm{CC}, \mathrm{CT}$ & $17(81.0)$ & $107(89.2)$ & 1 & 0.286 \\
\hline rs1016343 & & & $\mathrm{TT}$ & $4(19.0)$ & $13(10.8)$ & $\begin{array}{c}1.94 \\
(0.56-6.64)\end{array}$ & \\
\hline
\end{tabular}


TABLE 2: Continued.

\begin{tabular}{|c|c|c|c|c|c|c|c|}
\hline \multirow[t]{2}{*}{$\begin{array}{l}\text { Gene } \\
\text { polymorphism }\end{array}$} & \multirow[t]{2}{*}{ Allele change } & \multirow[t]{2}{*}{$\begin{array}{l}\text { Minor allele } \\
\text { frequency }\end{array}$} & \multirow[t]{2}{*}{$\begin{array}{c}\text { Grouped } \\
\text { genotypes }\end{array}$} & \multicolumn{2}{|c|}{$\begin{array}{c}\text { Bleeding complications, } \\
\text { number }(\%)\end{array}$} & \multirow[t]{2}{*}{ OR (95\% CI) } & \multirow[t]{2}{*}{$P$} \\
\hline & & & & $\begin{array}{c}\text { Presence } \\
(\mathrm{n}=21)\end{array}$ & $\begin{array}{l}\text { Absence } \\
(\mathrm{n}=121)\end{array}$ & & \\
\hline $8 \mathrm{q} 24$ & $A>G$ & 0.391 & $\mathrm{AA}, \mathrm{AG}$ & $12(57.1)$ & $77(63.6)$ & 1 & 0.570 \\
\hline rs10505477 & & & GG & $9(42.9)$ & $44(36.4)$ & $\begin{array}{c}1.31 \\
(0.51-3.36)\end{array}$ & \\
\hline $8 \mathrm{q} 24$ & $\mathrm{G}>\mathrm{T}$ & 0.261 & GG, GT & $17(81.0)$ & $112(92.6)$ & 1 & 0.089 \\
\hline rs9642880 & & & TT & $4(19.0)$ & $9(7.4)$ & $\begin{array}{c}2.93 \\
(0.81-10.57)\end{array}$ & \\
\hline $8 \mathrm{q} 24$ & $A>G$ & 0.465 & $\mathrm{AA}, \mathrm{AG}$ & $19(90.5)$ & $81(66.9)$ & 1 & 0.029 \\
\hline rs13281615 & & & GG & $2(9.5)$ & $40(33.1)$ & $\begin{array}{c}0.21 \\
(0.05-0.96)\end{array}$ & \\
\hline $8 \mathrm{q} 24$ & $\mathrm{~T}>\mathrm{C}$ & 0.170 & TT, TC & $21(100.0)$ & $113(94.2)$ & 1 & 0.256 \\
\hline rs1562430 & & & CC & $0(0.0)$ & $7(5.8)$ & $\begin{array}{c}0.94 \\
(0.90-0.98)^{*}\end{array}$ & \\
\hline $8 \mathrm{q} 24$ & $A>G$ & 0.278 & AA & $3(14.3)$ & $7(5.8)$ & 1 & 0.160 \\
\hline rs7014346 & & & AG, GG & $18(85.7)$ & $114(94.2)$ & $\begin{array}{c}0.37 \\
(0.09-1.57)\end{array}$ & \\
\hline Myc & $\mathrm{C}>\mathrm{T}$ & 0.113 & $\mathrm{CC}, \mathrm{CT}$ & $21(100.0)$ & $120(99.2)$ & 1 & 0.676 \\
\hline rs4645957 & & & TT & $0(0)$ & $1(0.8)$ & $\begin{array}{c}0.99 \\
(0.98-1.01)^{*}\end{array}$ & \\
\hline Myc & $\mathrm{C}>\mathrm{T}$ & 0.150 & $\mathrm{CC}, \mathrm{CT}$ & $20(95.2)$ & 117 (98.3) & 1 & 0.369 \\
\hline rs4645948 & & & TT & $1(4.8)$ & $2(1.7)$ & $\begin{array}{c}2.93 \\
(0.25-33.79)\end{array}$ & \\
\hline Myc & $\mathrm{T}>\mathrm{C}$ & 0.011 & TT & $21(100.0)$ & 118 (97.5) & 1 & 0.466 \\
\hline rs4645962 & & & TC, CC & $0(0.0)$ & $3(2.5)$ & $\begin{array}{c}0.98 \\
(0.95-1.01)^{*}\end{array}$ & \\
\hline Myc & $\mathrm{C}>\mathrm{T}$ & 0.302 & $\mathrm{CC}$ & $8(42.1)$ & $55(49.1)$ & 1 & 0.572 \\
\hline rs4645943 & & & CT, TT & $11(57.9)$ & $57(50.9)$ & $\begin{array}{c}1.33 \\
(0.50-3.55)\end{array}$ & \\
\hline$M y c$ & $\mathrm{C}>\mathrm{T}$ & 0.159 & $\mathrm{CC}$ & $11(61.1)$ & $84(73.7)$ & 1 & 0.270 \\
\hline rs 4645974 & & & CT, TT & 7 (38.9) & $30(26.3)$ & $\begin{array}{c}1.78 \\
(0.63-5.02)\end{array}$ & \\
\hline
\end{tabular}

* Data are expressed as relative risks.

${ }^{\mathrm{a}}$ Patients with the CC genotype were not found in this study.

TABLE 3: Multivariate analysis to identify predictors for bleeding complications at a therapeutic INR.

\begin{tabular}{|c|c|c|c|}
\hline Variables & Adjusted OR (95\% CI) & $\begin{array}{c}\text { Attributable risk } \\
(\%)\end{array}$ & $\mathrm{NNG}^{\mathrm{a}}$ \\
\hline Atrial fibrillation & $5.50(1.30-23.36)^{*}$ & 81.83 & \\
\hline $\begin{array}{l}8 \mathrm{q} 24 \\
\text { rs6983561, CC }\end{array}$ & $27.64(3.63-210.29)^{* *}$ & 96.38 & 36.8 \\
\hline $\begin{array}{l}8 \mathrm{q} 24 \\
\mathrm{rs} 13281615, \mathrm{AA}, \mathrm{AG}\end{array}$ & $10.00(1.47-68.6)^{*}$ & 90.00 & 8.3 \\
\hline
\end{tabular}

Logistic regression analyses were carried out with variables of sex, age, atrial fibrillation, rs6983561, and rs13281615.

${ }^{*} p<0.05 ;{ }^{* *} p<0.01$.

${ }^{a}$ Number needed to genotype $(\mathrm{NNG})$ was calculated with the formula $1 /$ (attributable risk $\times$ proportion of patients with both bleeding complications and risk genotypes). 
and alter Myc expression [11,27]. In genome-wide association studies, 8q24 polymorphisms were also identified as cancerrelated variant. As $M y c$ is widely known as protooncogene, the effect of 8q24 polymorphisms was explained to be Mycmediated in those studies $[27,28]$.

Rs6983561, along with its LD correlates (rs16901979 and rs10505483), is one of the SNPs that were significantly associated with bleeding complications in our study. It is located in the most centromeric region of $8 \mathrm{q} 24$, called region 2 (128.14-128.28 Mb). Some polymorphisms in region 2, including rs6983561 and rs16901979, have consistently shown strong associations with prostate cancer. It was explained that the polymorphisms possibly affect Myc expression, thereby increasing cancer risk $[29,30]$. Our result showed that cancerrisk variants also increased bleeding complications, implying that bleeding is caused by alterations of Myc expression.

Rs13281615 is known to be associated with breast cancer [31]. Interestingly, this variant allele, which is reported to increase breast cancer risk, showed a protective effect against bleeding complications in our study. Some studies have suggested that this SNP does not involve a cis-regulatory element for Myc expression and alters plasmacytoma variant translocation 1 (PVT1) expression, indicating that this SNP might be involved in different mechanisms for bleeding from those of other variants $[28,31]$.

In our study, VKORC1 and CYP2C9 polymorphisms were not significantly different in terms of bleeding complications. Although VKORC1 and CYP2C9 are known to affect warfarin dose [2], our study patients, who already had dosing adjustments according to INR measurements, were expected not to be affected by VKORC1 and CYP2C9 polymorphisms.

We found that atrial fibrillation was a risk factor for bleeding complications. A study has reported that atrial fibrillation increases the bleeding risk [32]. However, there is also conflicting report about the impact of atrial fibrillation on bleeding complications [33]. Further research needs to be performed to confirm the association between atrial fibrillation and bleeding.

The NNG for preventing bleeding complications in patients with high-risk genotypes was calculated to show the clinical significance and cost-effectiveness of genotyping. The NNGs of rs6983561 and rs13281615 were 36.8 and 8.3, respectively, which implies that genotyping for these SNPs before treatment might be helpful for reducing the risk of bleeding complications associated with warfarin.

Although this study was limited by its retrospective design and small sample size, to our knowledge this was the first study to investigate the association between Myc-related genes-including 8q24 polymorphisms-and warfarin-related bleeding complications. Moreover, we calculated the attributable risks and NNGs of each high-risk SNP, which can be used to individualize warfarin therapy. Since this study dealt with patients with INR 2-3, only minimal or minor bleeding events were observed. While there is no doubt that fatal and major hemorrhages are of essential importance, minor bleedings are also important, since they serve as an alert for subsequent major bleedings and may increase the number of visits to clinics and sometimes the emergency room (ER), which results in additional expenditures. They also can result in permanent withdrawal of warfarin therapy, thus depriving patients of the effective therapy available.

\section{Conclusions}

This study showed that two SNPs of 8q24 (rs6983561 and rs13281615) were associated with bleeding complications at a therapeutic INR during warfarin treatment for mechanical heart valve patients. Given the retrospective study design and the relatively small sample size, our hypothesis requires further independent validation using prospective study design with large sample size.

\section{Data Availability}

The data used to support the findings of this study are available from the corresponding author upon request.

\section{Conflicts of Interest}

The authors have no conflicts of interest to declare.

\section{Authors' Contributions}

Jeong Yee and Woorim Kim equally contributed to this work.

\section{Acknowledgments}

This study was supported by Basic Science Research Program through the National Research Foundation (NRF) of Korea funded by the Ministry of Education [grant number 2017R1D1A1B03034033] and by the Overseas Dispatch Program of Chungbuk National University in 2017.

\section{References}

[1] M. Pirmohamed, "Warfarin: almost 60 years old and still causing problems," British Journal of Clinical Pharmacology, vol. 62, no. 5, pp. 509-511, 2006.

[2] D. M. Roden, J. A. Johnson, S. E. Kimmel et al., "Cardiovascular pharmacogenomics," Circulation Research, vol. 109, no. 7, pp. 807-820, 2011.

[3] R. A. Nishimura, C. M. Otto, R. O. Bonow et al., "2014 AHA/ACC guideline for the management of patients with valvular heart disease: executive summary: a report of the american college of cardiology/american heart association task force on practice guidelines," Circulation, vol. 129, no. 23, pp. 2440-2492, 2014.

[4] J. Ansell, J. Hirsh, E. Hylek et al., "American college of chest physicians. pharmacology and management of the vitamin $\mathrm{k}$ antagonists:american college of chest physicians evidencebased clinical practice guidelines," Chest, vol. 133, pp. 160S-198S, 2008.

[5] I. Marie, P. Leprince, J.-F. Menard, C. Tharasse, and H. Levesque, "Risk factors of vitamin K antagonist overcoagulation," QJM: An International Journal of Medicine, vol. 105, no. 1, pp. 53-62, 2012.

[6] E. Uygungül, C. Ayrik, H. Narci et al., "Determining risk factors of bleeding in patients on warfarin treatment," Advances in Hematology, vol. 2014, 2014. 
[7] P. B. Rahl and R. A. Young, "MYC and transcription elongation," Cold Spring Harbor Perspectives in Medicine, vol. 4, no. 1, 2014.

[8] C. A. Souders, S. L. K. Bowers, I. Banerjee, J. W. Fuseler, J. L. Demieville, and T. A. Baudino, "C-Myc Is required for proper coronary vascular formation via cell-and gene-specific signaling," Arteriosclerosis, Thrombosis, and Vascular Biology, vol. 32, no. 5, pp. 1308-1319, 2012.

[9] J. A. Cox, E. Bartlett, and E. I. Lee, "Vascular malformations: A review," Seminars in Plastic Surgery, vol. 28, no. 2, pp. 58-63, 2014.

[10] C. Grisanzio and M. L. Freedman, "Chromosome 8q24associated cancers and MYC," Genes \& Cancer, vol. 1, no. 6, pp. 555-559, 2010.

[11] J. Sotelo, D. Esposito, M. A. Duhagon et al., "Long-range enhancers on 8q24 regulate c-Myc," Proceedings of the National Acadamy of Sciences of the United States of America, vol. 107, no. 7, pp. 3001-3005, 2010.

[12] R. Mehran, S. V. Rao, D. L. Bhatt et al., "Standardized bleeding definitions for cardiovascular clinical trials: a consensus report from the bleeding academic research consortium," Circulation, vol. 123, no. 23, pp. 2736-2747, 2011.

[13] M. Whirl-Carrillo, E. M. McDonagh, J. M. Hebert, and J. M, "Pharmacogenomics knowledge for personalized medicine," Clinical Pharmacology Therapeutics, vol. 92, pp. 414-417, 2012.

[14] S. T. Sherry, M. H. Ward, M. Kholodov et al., "dbSNP: the NCBI database of genetic variation," Nucleic Acids Research, vol. 29, no. 1, pp. 308-311, 2001.

[15] L. D. Ward and M. Kellis, "HaploReg v4: Systematic mining of putative causal variants, cell types, regulators and target genes for human complex traits and disease," Nucleic Acids Research, vol. 44, no. 1, pp. D877-D881, 2016.

[16] M. M. Pomerantz, C. A. Beckwith, M. M. Regan et al., "Evaluation of the 8q24 prostate cancer risk locus and MYC expression," Cancer Research, vol. 69, no. 13, pp. 5568-5574, 2009.

[17] M. Du, T. Yuan, and K. F. Schilter, "Prostate cancer risk locus at $8 \mathrm{q} 24$ as a regulatory hub by physical interactions with multiple genomic loci across the genome," Human Molecular Genetics, vol. 24, no. 1, pp. 154-166, 2015.

[18] K. E. Lee, B. C. Chang, S. Park, and H. S. Gwak, "Effects of single nucleotide polymorphisms in c-Myc on stable warfarin doses in patients with cardiac valve replacements," Pharmacogenomics, vol. 16, no. 10, pp. 1101-1108, 2015.

[19] P. S. Knoepfler, "Myc goes global: New tricks for an old oncogene," Cancer Research, vol. 67, no. 11, pp. 5061-5063, 2007.

[20] C. Napoli, L. O. Lerman, F. De Nigris, and V. Sica, "c-Myc oncoprotein: A dual pathogenic role in neoplasia and cardiovascular diseases?" Neoplasia, vol. 4, no. 3, pp. 185-190, 2002.

[21] T. A. Baudino, C. McKay, H. Pendeville-Samain et al., "c-Myc is essential for vasculogenesis and angiogenesis during development and tumor progression," Genes \& Development, vol. 16, no. 19, pp. 2530-2543, 2002.

[22] Y. Shi, H. G. Hutchinson, D. J. Hall, and A. Zalewski, "Downregulation of c-myc expression by antisense oligonucleotides inhibits proliferation of human smooth muscle cells," Circulation, vol. 88, no. 3, pp. 1190-1195, 1993.

[23] L. A. Bashawri and M. A. Ahmed, "The approach to a patient with a bleeding disorder: for the primary care physician," Journal of Family \& Community Medicine, vol. 14, pp. 53-58, 2007.

[24] J. Bauditz and H. Lochs, "Angiogenesis and vascular malformations: Antiangiogenic drugs for treatment of gastrointestinal bleeding," World Journal of Gastroenterology, vol. 13, no. 45, pp. 5979-5984, 2007.

[25] J. S. Penn, A. Madan, R. B. Caldwell, M. Bartoli, R. W. Caldwell, and M. E. Hartnett, "Vascular endothelial growth factor in eye disease," Progress in Retinal and Eye Research, vol. 27, no. 4, pp. 331-371, 2008.

[26] C. J. Lockwood, "Mechanisms of normal and abnormal endometrial bleeding," Menopause, vol. 18, no. 4, pp. 408-411, 2011.

[27] M. M. Pomerantz, N. Ahmadiyeh, L. Jia et al., “The 8q24 cancer risk variant rs6983267 shows long-range interaction with MYC in colorectal cancer," Nature Genetics, vol. 41, no. 8, pp. 882-884, 2009.

[28] N. Ahmadiyeh, M. M. Pomerantz, C. Grisanzio et al., "8q24 prostate, breast, and colon cancer risk loci show tissue-specific long-range interaction with Myc," in Proceedings of the National Academy of Sciences of the United States of America, vol. 107, pp. 9742-9746, 2010.

[29] I. Cheng, S. J. Plummer, E. Jorgenson et al., " $8 \mathrm{q} 24$ and prostate cancer: Association with advanced disease and meta-analysis," European Journal of Human Genetics, vol. 16, no. 4, pp. 496-505, 2008.

[30] S. Chung, H. Nakagawa, M. Uemura et al., "Association of a novel long non-coding RNA in $8 \mathrm{q} 24$ with prostate cancer susceptibility," Cancer Science, vol. 102, no. 1, pp. 245-252, 2011.

[31] Z. Zhang, Z. Zhu, B. Zhang et al., "Frequent mutation of rs13281615 and its association with PVT1 expression and cell proliferation in breast cancer," Journal of Genetics and Genomics, vol. 41, no. 4, pp. 187-195, 2014.

[32] C. S. Landefeld and R. J. Beyth, "Anticoagulant-related bleeding: Clinical epidemiology, prediction, and prevention," American Journal of Medicine, vol. 95, no. 3, pp. 315-328, 1993.

[33] C. S. Landefeld and O. L. Goldman, "Major bleeding in outpatients treated with warfarin: incidence and prediction by factors known at the start of outpatient therapy," American Journal of Medicine, vol. 87, no. 2, pp. 144-152, 1989. 


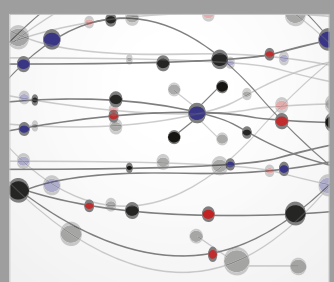

The Scientific World Journal
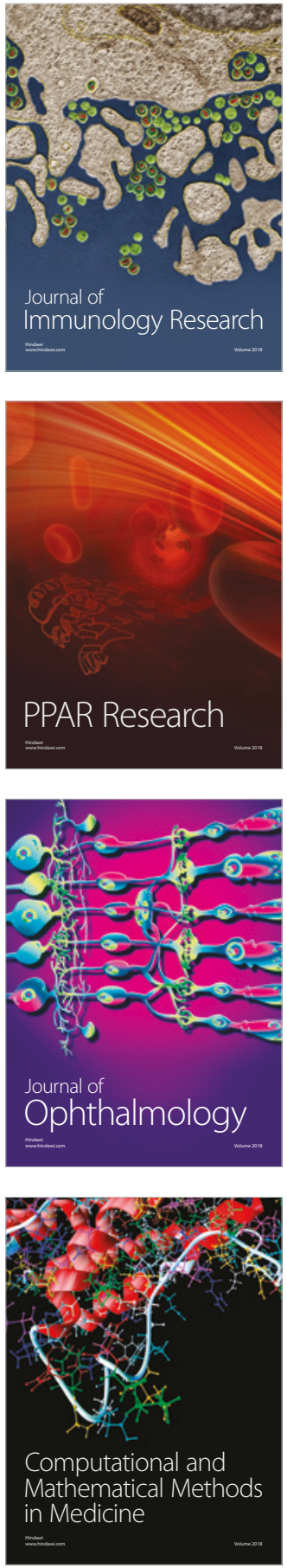

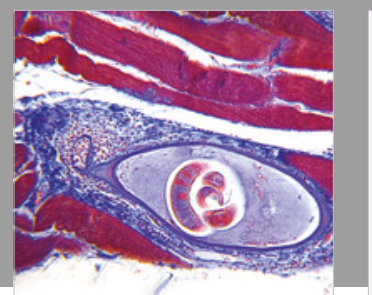

Gastroenterology Research and Practice

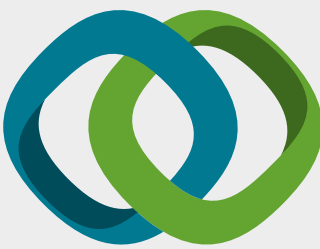

\section{Hindawi}

Submit your manuscripts at

www.hindawi.com
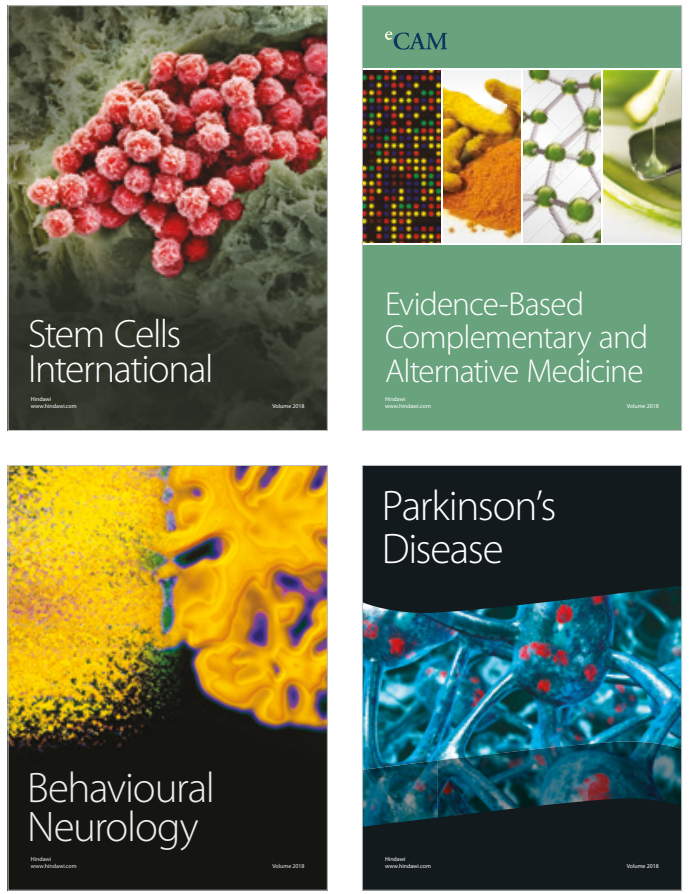

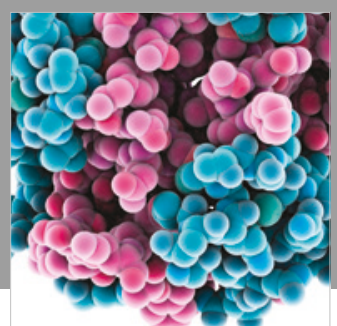

ournal of

Diabetes Research

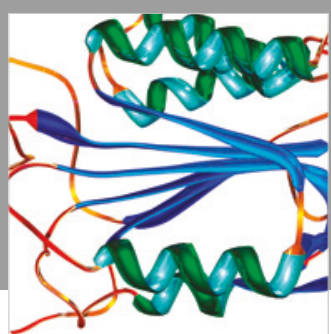

Disease Markers
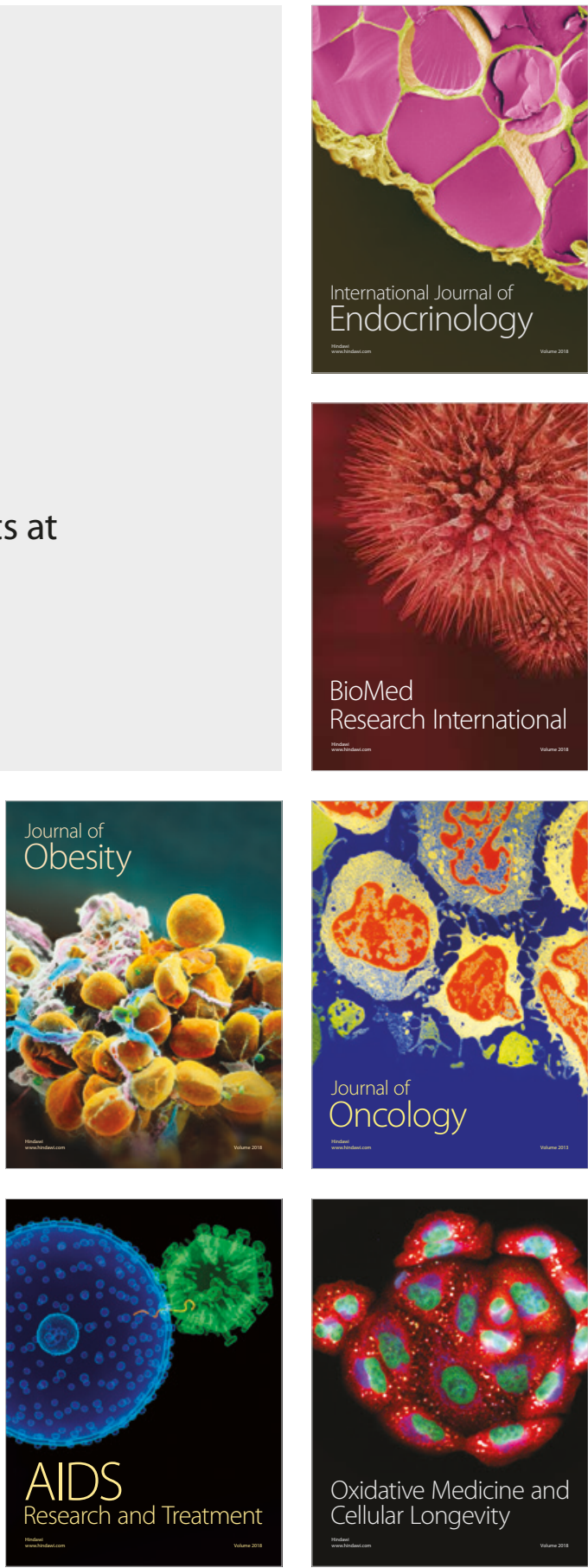